\title{
Faktor Risiko Trauma Lahir
}

\author{
MM. Tri Widiyati, Setya Wandita Tunjung Wibowo, Ekawaty Lutfia Haksari \\ Departemen Ilmu Kesehatan Anak Fakultas Kedokteran Universitas Gadjah Mada/ RS Sardjito, \\ Yogyakarta
}

Latar belakang. Kemajuan di bidang pelayanan obstetri berhasil menurunkan kejadian trauma lahir. Namun, trauma lahir masih merupakan salah satu penyebab morbiditas dan mortalitas pada neonatal. Banyak faktor risiko yang berperan dalam trauma lahir.

Tujuan. Mengetahui faktor risiko trauma lahir.

Metode. Penelitian kasus-kontrol di bangsal Perinatal Rumah Sakit Dr Sardjito, Yogyakarta, mulai Januari 2004 sampai Desember 2008. Kriteria inklusi adalah semua neonatus dengan trauma lahir dan kriteria eksklusi adalah jika ada anomali kongenital dan data medis tidak lengkap. Kontrol adalah neonatus tanpa trauma lahir. Kasus adalah semua neonatus dengan trauma lahir, dan keduanya memenuhi kriteria inklusi dan eksklusi. Data dikumpulkan dari rekam medis yang berkaitan dengan data ibu, bayi, dan faktor risiko yang diduga berhubungan dengan trauma lahir.

Hasil. Di antara 6678 neonatus, 47 mengalami trauma lahir, yaitu trauma kepala 27 (57\%), trauma tulang $13(28 \%)$, saraf perifer $10(21,3 \%)$, saraf pusat $7(14,8 \%)$, dan 3 lainnya $(6 \%)$. Faktor risiko trauma lahir adalah paritas (OR 1,3;CI95\%=0,5-3,4; p=0,625), umur kehamilan (OR 1,5;95\%CI=0,2-9,6; p=1,00), berat lahir (OR 1,4;95\%CI=0,3-6,5; p=0,100), lingkar kepala (OR 1,5;95\%CI=0,4-5,0; $\mathrm{p}=0,76)$, malpresentasi (OR 3,6;95\%CI=0,4-30,3;p=0,244), presentasi bokong (OR 3,9;95\% $\mathrm{CI}=1,0-14,8 ; \mathrm{p}=0,049)$, presentasi muka (OR 2,0;95\%CI=1,7-2,5; $\mathrm{p}=1,00)$, vakum ekstraksi (OR 10,1;95\%CI=1,2-88,3; $\mathrm{p}=0,037)$, versi ekstraksi (OR 3,1;95\%CI=0,3-31,3; p=0,62), penyulit persalinan (OR 11,4;95\%CI=2,2-60,2; $\mathrm{p}=0,004)$, letak lintang $(\mathrm{OR} 1,0 ; 95 \% \mathrm{CI}=0,2-5,2 ; \mathrm{p}=1,000)$, dan seksio kaisaria $(\mathrm{OR}$ 0,4;95\%CI=0,1-0,8; $\mathrm{p}=0,017)$.

Kesimpulan. Faktor risiko trauma lahir adalah presentasi bokong, persalinan dengan penyulit dan vakum ekstraksi, sedangkan kelainan presentasi tidak berhubungan dengan trauma lahir. Seksio kaisaria merupakan faktor protektif terhadap terjadinya trauma lahir. Sari Pediatri 2014;15(5):294-300.

Kata kunci: trauma lahir, neonatus, faktor risiko

\footnotetext{
Alamat korespondensi:

Dr. Maria Magdalena Tri Widiyati. Bagian Ilmu Kesehatan Anak, RSUP Dr Sardjito, Fakultas Kedokteran Universitas Gadjah Mada, Jl Kesehatan No 1 Sekip Yogyakarta 55284, Indonesia. Telp. (0274) 561616, Fax. (0274) 583745, E-mail: widinaya3000@yahoo.com
}

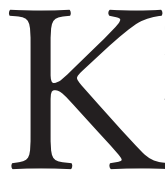
emajuan di bidang pelayanan obstetri telah berhasil menurunkan insiden trauma lahir. Namun, trauma lahir masih merupakan salah 1 satu penyebab morbiditas dan mortalitas pada neonatal. Trauma lahir merupakan akibat trauma mekanik selama proses kelahiran yang merupakan gabungan dari kekuatan kontraksi kompresi, putaran, 
dan tarikan. Beberapa faktor risiko yang berperan dalam trauma lahir adalah 1) faktor ibu yang berkaitan dengan kekakuan jalan lahir (primipara, multipara, malformasi, dan panggul sempit); 2) faktor bayi yang berkaitan dengan diskrepansi antara besar serta posisi bayi dengan jalan lahir (makrosomia, makrosefalia, anomali fetus, disproporsi sefalopelvik, distosia bahu, presentasi abnormal seperti bokong, muka, dahi dan letak lintang; prematur, partus prsipitatus; 3 ) faktor luar yang berupa tindakan persalinan (pemakaian forseps, vakum, tindakan versi-ekstraksi). ${ }^{1}$

Insiden trauma lahir 6-8 kasus per 1000 kelahiran hidup. Kurang dari 2\% kematian neonatus disebabkan oleh trauma lahir. Dalam kurun waktu 1970-1985, angka kematian ini menurun drastis dari 64,2\% menjadi 7,5\% per 100.000 kelahiran hidup. Penurunan ini merupakan dampak kemajuan bidang pelayanan obstetri dalam mendeteksi faktor risiko menggunakan ultrasonografi dan pemantauan fetus sebelum dan selama proses persalinan. Penyebab lain adalah penggantian tindakan ekstraksi forsep dan vakum dalam persalinan dengan tindakan bedah kaisar yang dinilai lebih aman untuk bayi. ${ }^{1,2}$ Zaman $\mathrm{dkk}^{3}$ juga mendukung bahwa dengan tindakan seksio kaisar akan mengurangi terjadinya tekanan dan tarikan selama proses persalinan sehingga menurunkan insiden trauma lahir.

Trauma lahir penting untuk mendapatkan perhatian karena pada beberapa kasus dapat berakibat fatal dan dapat menyebabkan kecacatan fisik maupun gangguan perkembangan di tahap usia selanjutnya. Trauma lahir ini juga sering dijumpai dalam praktek sehari-hari sehingga perlu dijelaskan kepada orang tua tentang tentang diagnosis, tata laksana, dan juga prognosisnya. Dengan mengetahui faktor risiko yang berperan terhadap terjadinya trauma lahir maka diharapkan dapat dilakukan antisipasi untuk usaha pencegahan untuk memberikan outcome yang terbaik bagi neonatus dan keluarganya. Berdasarkan latar belakang tersebut maka penelitian ini dilakukan untuk mengetahui faktor risiko yang berhubungan dengan terjadinya trauma lahir.

\section{Metode}

Penelitian kasus-kontrol dimulai dengan identifikasi subjek tanpa trauma lahir (kelompok kontrol) dan dengan trauma lahir (kelompok kasus). Penelusuran catatan medis neonatus yang dirawat mulai Januari
2004 sampai Desember 2008 di bagian Perinatal RSUP Dr Sardjito, Yogyakarta. Kelompok kasus adalah neonatus dengan trauma lahir yang memenuhi kriteria inklusi dan eksklusi. Kelompok kontrol adalah neonatus tanpa trauma lahir yang memenuhi kriteria inklusi dan eksklusi. Kriteria inklusi adalah semua neonatus dengan maupun tanpa trauma lahir, data rekam medis lengkap, dan tanpa kelainan kongenital.

Besar sampel untuk penelitian kasus kontrol berpasangan, ${ }^{4}$ proporsi efek pada kontrol $\left(\mathrm{P}_{2}\right)=7,5 \%{ }^{1}$; OR yang dianggap bermakna secara klinis adalah $2(\mathrm{OR}=2)$; tingkat kemaknaan: $\alpha=0,05 ; \mathrm{Z} \alpha=1,96$ (ditetapkan oleh peneliti); power $80 \%$ atau $Z_{\beta}=0,842$ $(\beta=0,20)$ sehingga besar sampel untuk masing-masing kelompok adalah 68 neonatus, dengan total sampel 136 subjek. Data pasien termasuk data ibu, bayi, dan faktor risiko yang diduga berhubungan dengan trauma lahir.

Data dianalisis menggunakan persentase atau proporsi distribusi frekuensi. Chi-square dengan $\mathrm{p}<0,05$ didefinisikan sebagai signifikansi statistik. Rasio odds (OR) untuk menunjukkan kekuatan hubungan antara setiap faktor risiko dengan terjadinya trauma lahir dengan $\mathrm{OR}=2$ didefinisikan sebagai signifikansi statistik. Analisis regresi logistik untuk menunjukkan hubungan antara beberapa faktor risiko trauma lahir. Penelitian ini disetujui oleh Komite Etik Penelitian Kedokteran dan Kesehatan Fakultas Kedokteran, Universitas Gadjah Mada.

\section{Hasil}

Sembilanpuluh empat jumlah subjek yang memenuhi kriteria inklusi dan eksklusi dengan distribusi 47 kasus dan 47 kontrol. Subjek laki-laki didapatkan 60 (63,8\%) dan perempuan 34 (36,2\%). Selama penelitian terdapat 6678 kelahiran, dengan angka kejadian trauma lahir 7 per 1000 kelahiran hidup. Deskripsi dan distribusi karakteristik dasar subjek penelitian pada kedua kelompok subjek tertera pada Tabel 1, serta riwayat kehamilan ibu dan persalinan pada Tabel 2 .

Analisis univariat dan multivariat dilakukan untuk mengidentifikasi variabel independen yang berhubungan dengan trauma lahir. Berdasarkan analisis univariat, faktor risiko trauma lahir adalah primi gravida, presentasi bokong, persalinan dengan penyulit dan persalinan dengan alat (vakum ekstraksi), sedangkan tindakan seksio kaisaria merupakan 
Tabel 1. Karakteristik dasar subjek penelitian

\begin{tabular}{|c|c|c|c|}
\hline Variabel & Kasus $(\mathrm{n}=47)$ & Kontrol $(n=47)$ & Total \\
\hline Jenis kelamin, $\mathrm{n}(\%)$ & & & $94(100)$ \\
\hline Laki-laki & $33(70,2)$ & $27(57,5)$ & $60(63,8)$ \\
\hline Perempuan & $14(29,8)$ & $20(42,5)$ & $34(37,2)$ \\
\hline Tempat tinggal, n (\%) & & & $94(100)$ \\
\hline Kodya & $10(21,3)$ & $15(31,9)$ & $25(26,6)$ \\
\hline Sleman & $25(53,2)$ & $23(48,9)$ & $48(51,1)$ \\
\hline Bantul & $8(17,0)$ & $6(12,8)$ & $14(14,9)$ \\
\hline Kulon Progo & $0(0,0)$ & $1(2,1)$ & $1(1,1)$ \\
\hline Gunung Kidul & $1(2,1)$ & $1(2,1)$ & $2(2,2)$ \\
\hline Luar kota & $3(6,4)$ & $1(2,1)$ & $4(4,4)$ \\
\hline \multicolumn{4}{|l|}{ Tingkat pendidikan, n (\%) } \\
\hline Ibu, n (\%) & $47(100)$ & $47(100)$ & $94(100)$ \\
\hline Tidak sekolah & $0(0)$ & $0(0,0)$ & $0(0)$ \\
\hline $\mathrm{SD}$ & $7(14,9)$ & $1(2,1)$ & $8(8,5)$ \\
\hline SLTP & $10(21,3)$ & $7(14,9)$ & $17(18,1)$ \\
\hline SLTA & $15(31,9)$ & $23(48,9)$ & $38(40,4)$ \\
\hline Sarjana & $15(31,9)$ & $16(34,0)$ & $31(33,0)$ \\
\hline Missing data & $0(0,0)$ & $0(0,0)$ & $0(0,0)$ \\
\hline Ayah, n (\%) & $47(100)$ & $44(93,6)$ & $91(96,8)$ \\
\hline Tidak sekolah & $1(2,1)$ & $0(0,0)$ & $1(1,1)$ \\
\hline $\mathrm{SD}$ & $4(8,5)$ & $1(2,1)$ & $5(5,3)$ \\
\hline SLTP & $9(19,2)$ & $4(8,5)$ & $13(13,8)$ \\
\hline SLTA & $19(40,4)$ & $21(44,7)$ & $40(42,6)$ \\
\hline Sarjana & $14(29,8)$ & $18(38,3)$ & $32(34,0)$ \\
\hline Missing data & $0(0,0)$ & $3(6,4)$ & $3(3,2)$ \\
\hline \multicolumn{4}{|l|}{ Pekerjaan, n (\%) } \\
\hline Ibu, n (\%) & $47(100)$ & $47(100)$ & $94(100)$ \\
\hline Tidak bekerja/IRT & $30(63,8)$ & $26(55,3)$ & $56(59,6)$ \\
\hline PNS/ABRI & $3(6,4)$ & $3(6,4)$ & $6(6,4)$ \\
\hline Buruh & $0(0,0)$ & $0(0,0)$ & $0(0,0)$ \\
\hline Petani & $1(2,1)$ & $1(2,1)$ & $2(2,1)$ \\
\hline Tenaga kesehatan & $3(6,4)$ & $2(4,2)$ & $5(5,3)$ \\
\hline Swasta & $10(21,3)$ & $15(31,9)$ & $25(26,6)$ \\
\hline Missing data & $0(0,0)$ & $0(0,0)$ & $0(0,0)$ \\
\hline Ayah, n (\%) & $47(100)$ & $43(91,5)$ & $90(95,8)$ \\
\hline Tidak bekerja/IRT & $3(6,4)$ & $0(0,0)$ & $3(3,2)$ \\
\hline PNS/ABRI & $5(10,6)$ & $5(10,6)$ & $10(10,6)$ \\
\hline Buruh & $8(17,0)$ & $4(8,4)$ & $12(12,8)$ \\
\hline Petani & $3(6,4)$ & $1(2,1)$ & $4(4,3)$ \\
\hline Tenaga kesehatan & $2(4,2)$ & $2(4,2)$ & $4(4,3)$ \\
\hline Swasta & $25(53,2)$ & $30(63,8)$ & $55(58,5)$ \\
\hline Missing data & $0(0,0)$ & $4(8,4)$ & $4(4,3)$ \\
\hline Tempat persalinan, $\mathrm{n}(\%)$ & $47(100)$ & $47(100)$ & $94(100)$ \\
\hline Rumah bersalin & $15(31,9)$ & $2(4,2)$ & $17(18,1)$ \\
\hline RSUD & $7(14,9)$ & $1(2,1)$ & $8(8,6)$ \\
\hline RS Swasta & $1(2,1)$ & $1(2,1)$ & $2(2,1)$ \\
\hline RS Sardjito & $24(51,1)$ & $43(91,5)$ & $67(71,3)$ \\
\hline
\end{tabular}


Tabel 2. Riwayat kehamilan dan persalinan

\begin{tabular}{|c|c|c|c|}
\hline Variabel & Kasus $(n=47)$ & Kontrol $(n=47)$ & Total \\
\hline \multicolumn{4}{|l|}{ Paritas, (n\%) } \\
\hline Primigravida & $30(63,8)$ & $23(48,9)$ & $53(56,4)$ \\
\hline Multi gravida & $17(36,2)$ & $24(51,1)$ & $41(43,6)$ \\
\hline \multicolumn{4}{|l|}{ Umur kehamilan, (n\%) } \\
\hline Preterm & $3(6,4)$ & $2(4,3)$ & $5(5,3)$ \\
\hline Aterm & $44(93,6)$ & $45(95,7)$ & $89(94,7)$ \\
\hline \multicolumn{4}{|l|}{ Presentasi, (n\%) } \\
\hline Belakang kepala & $31(66)$ & $40(85,1)$ & $71(75,5)$ \\
\hline Dahi & $1(2,1)$ & 0 & $1(1,1)$ \\
\hline Muka & $1(2,1)$ & 0 & $1(1,1)$ \\
\hline Bokong & $10(21,3)$ & $4(8,5)$ & $15(16)$ \\
\hline Lintang & $4(8,5)$ & $3(6,4)$ & $7(7,5)$ \\
\hline \multicolumn{4}{|l|}{ Berat badan lahir, (n\%) } \\
\hline Makrosomia & $4(8,5)$ & $3(6,4)$ & $7(7,5)$ \\
\hline Normal/rendah & $43(91,5)$ & $44(93,6)$ & $87(92,6)$ \\
\hline \multicolumn{4}{|l|}{ Lingkar kepala, (n\%) } \\
\hline Makrosefal & $7(14,9)$ & $5(10,6)$ & $12(12,8)$ \\
\hline Normal/Mikrosefal & $40(85,1)$ & $42(89,4)$ & $82(87,2)$ \\
\hline \multicolumn{4}{|l|}{ Cara persalinan, $(\mathrm{n} \%)$} \\
\hline Spontaneous & $20(42,7)$ & $23(48,9)$ & $43(45,8)$ \\
\hline Vakum ekstraksi & $9(19,1)$ & 0 & $9(9,6)$ \\
\hline Bracht/Manual aid & $5(10,6)$ & $1(2,2)$ & $6(6,4)$ \\
\hline Versi ekstraksi & $4(8,5)$ & 0 & $4(4,3)$ \\
\hline Seksio kaisaria & $9(19,1)$ & $23(48,9)$ & $32(34)$ \\
\hline \multicolumn{4}{|l|}{ Penolong persalinan, $(\mathrm{n} \%)$} \\
\hline Dokter/SpOG & $37(78,7)$ & $45(95,7)$ & $82(87,2)$ \\
\hline Bidan & $10(21,3)$ & $2(4,3)$ & $12(12,8)$ \\
\hline \multicolumn{4}{|l|}{ Tipe trauma lahir, (n\%) } \\
\hline Kepala & $27(57,5)$ & 0 & $27(28,7)$ \\
\hline Tulang & $13(27,7)$ & 0 & $13(13,8)$ \\
\hline Syaraf perifer & $10(21,3)$ & 0 & $10(10,6)$ \\
\hline Otak & $5(10,6)$ & 0 & $5(5,3)$ \\
\hline Lain-lain & $5(10,6)$ & 0 & $5(5,3)$ \\
\hline \multicolumn{4}{|l|}{ Penyulit persalinan, (n\%) } \\
\hline Distokia bahu & $7(14,9)$ & 0 & $7(7,5)$ \\
\hline Disproporsi kepala panggul & $1(2,1)$ & $1(2,1)$ & $2(2,2)$ \\
\hline Tanpa penyulit & $39(83,0)$ & $46(97,9)$ & $85(90,3)$ \\
\hline
\end{tabular}

faktor protektif terhadap kejadian trauma lahir. Jika $\mathrm{p}<0,25$ atau $\mathrm{p}>0,25$, tetapi variabel dianggap penting maka variabel tersebut dimasukkan dalam analisis multivariat. Hasil analisis univariat dan multivariat hubungan antara faktor risiko dengan trauma lahir tertera pada Tabel 3.

Hasil analisis multivariat menunjukkan faktor risiko yang berhubungan dengan kejadian trauma lahir adalah presentasi bokong (OR3,9; 95\% CI=1,0$14,8 ; \mathrm{p}=0,049)$, persalinan dengan penyulit (OR11,4; $95 \% \mathrm{CI}=2,2-60,2 ; \mathrm{p}=0,004)$ dan vakum ekstraksi (OR 10,1; 95\% CI=1,2-88,3; $\mathrm{p}=0,037)$, sedangkan seksio kaisaria merupakan faktor protektif terhadap trauma lahir (OR0,005; 95\%CI=0,1-0,8; $\mathrm{p}=0,017)$. 
MM. Tri Widiyati dkk: Faktor risiko trauma lahir

Tabel 3. Univariat dan regresi logistik analisis hubungan antara faktor risiko dengan DSS

\begin{tabular}{|c|c|c|c|c|c|}
\hline \multirow{2}{*}{ Faktor risiko } & \multicolumn{2}{|c|}{ Univariat $^{*}$} & \multirow{2}{*}{$\mathrm{p}$} & \multicolumn{2}{|c|}{ Multivariat* } \\
\hline & OR & $95 \% \mathrm{CI}$ & & OR & $95 \% \mathrm{CI}$ \\
\hline \multicolumn{6}{|l|}{ Paritas } \\
\hline Primigravida & 1,8 & $0,8-4,2$ & $0,21^{* *}$ & 1,3 & $0,5-3,4$ \\
\hline \multicolumn{6}{|l|}{ Umur kehamilan } \\
\hline Preterm & 1,5 & $0,2-9,6$ & $1,00^{*}$ & & \\
\hline \multicolumn{6}{|l|}{ Berat badan lahir } \\
\hline Makrosomia & 1,4 & $0,3-6,5$ & $1,00^{*}$ & & \\
\hline \multicolumn{6}{|l|}{ Lingkar kepala } \\
\hline Makrosefal & 1,5 & $0,4-5,0$ & $0,76^{* *}$ & & \\
\hline \multicolumn{6}{|l|}{ Presentasi } \\
\hline Malpresentasi & 2,7 & $1,0-7,4$ & $0,09^{* *}$ & 3,6 & $0,4-30,3$ \\
\hline Presentasi bokong & 2,6 & $0,7-8,9$ & $0,23^{* *}$ & 3,9 & $1,0-14,8$ \\
\hline Presentasi muka & 2,0 & $1,7-2,5$ & $1,00^{* *}$ & & \\
\hline Letak lintang & 1,0 & $0,2-5,2$ & $1,00^{*}$ & & \\
\hline Vakum ekstraksi & 10,9 & $1,3-89,9$ & $0,02^{* *}$ & 10,1 & $1,2-88,3$ \\
\hline Versi ekstraksi & 3,1 & $0,3-31,3$ & $0,62^{*}$ & & \\
\hline Seksio Kaisar & 0,3 & $0,1-0,7$ & $0,008^{* *}$ & 0,4 & $0,1-0,8$ \\
\hline Penyulit persalinan & 6,3 & $2,4-16,9$ & $0,00^{* *}$ & 11,4 & $2,2-60,2$ \\
\hline
\end{tabular}

* Fisher's Exact Test

** Continuity Correction

\section{Pembahasan}

Trauma lahir masih merupakan masalah utama dalam pelayanan obstetri. Faktor-faktor yang diduga berhubungan dengan trauma lahir adalah makrosomia, disproporsi kepala panggul, persalinan dengan penyulit, presentasi bokong (letak sungsang), dan penggunaan alat pada proses persalinan. Secara keseluruhan, 5-8 neonatus per 100.000 kelahiran hidup meninggal akibat trauma lahir, sementara 25 neonatus per 100.000 kelahiran hidup meninggal akibat hipoksia. ${ }^{5}$ Menurut Garcia dkk, ${ }^{6}$ faktor risiko yang berhubungan dengan trauma lahir adalah faktor maternal, bayi, dan proses persalinan. Kami mendapatkan insiden trauma lahir 0,7\% (47 kasus dari 6678 neonatus). Hasil tersebut sesuai dengan insiden di negara barat sekitar 7 per 1000 kelahiran hidup, sedangkan Tabatabaei, ${ }^{7}$ Mosavat, dan Zamani di Iran, ${ }^{5}$ melaporkan insiden trauma lahir $0,8 \%$.

Angka kejadian trauma lahir pada primigravida $63,8 \%$. Namun, wanita primi gravida mempunyai risiko yang lebih tinggi dibandingkan dengan multigravida, hal tersebut dipengaruhi faktor kekakuan jalan lahir. Hasil penelitian kami sesuai dengan penelitian lain yang mendapatkan hasil bahwa paritas tidak terbukti sebagai faktor risiko trauma lahir. ${ }^{8}$ Penelitian kami juga sesuai dengan teori yang menyebutkan bahwa insiden trauma lahir lebih tinggi pada kelompok nullipara yang disebabkan kurangnya pengalaman melahirkan, trauma tekanan akibat kontraksi pelvis, dan distokia tulang dan jaringan lunak pada jalan lahir., ${ }^{9,10}$

Usia kehamilan menunjukkan hasil yang tidak bermakna. Hal tersebut tidak sesuai dengan penelitian Borna $\mathrm{dkk}^{11}$ di Taiwan yang mendapatkan hasil bahwa faktor risiko yang berhubungan dengan trauma lahir yaitu persalinan dengan induksi, ketuban pecah dini, tingkat pendidikan penolong persalinan, makrosomia, persalinan dengan bantuan alat, dan usia kehamilan.

Berdasarkan berat badan lahir, insiden trauma lahir lebih tinggi pada neonatus dengan berat lahir $>4000$ g $(8,5 \%)$ dibandingkan normal/BBLR (6,4\%). Hasil tersebut sesuai dengan penelitian lain di negara Barat yang melaporkan angka kejadian trauma lahir lebih tinggi pada bayi berat $>4000 \mathrm{~g}$. Penelitian retrospektif lain juga menunjukkan hasil yang sama, yaitu sebuah penelitian di Philadelphia selama 3 tahun, periode 2003 sampai 2005 dengan hasil bahwa bayi makrosomia merupakan kelompok risiko tinggi, terutama kelompok $>4500$ g mempunyai outcome yang jelek. ${ }^{12}$

Hasil penelitian kami makrosomia tidak terbukti sebagai faktor risiko trauma lahir, berbeda dengan penelitian Mosavat dan Zamani ${ }^{5}$ yang menunjukkan 
bahwa makrosomia dan persalinan normal merupakan prediktor kuat terjadinya trauma lahir. Penelitian kami juga berbeda dengan Fabamwo $\mathrm{dkk}^{13}$ yang mendapatkan hasil bahwa insiden trauma lahir lebih tinggi pada neonatus dengan berat lahir normal. Kejadian trauma lahir yang tinggi pada makrosomia juga dipengaruhi pelayanan obstetri, kurang trampilnya kemampuan tenaga penolong persalinan, dan adanya penyulit persalinan. Hoeksma dkk ${ }^{14}$ mendapatkan hasil bahwa trauma pleksus brakhialis paling sering dijumpai pada persalinan dengan bayi besar (makrosomia). Lingkar kepala menunjukkan hasil tidak ada perbedaan antara makrosefal dengan normo/mikrosefal]. Hal tersebut disebabkan karena perbedaan lingkar kepala antara kedua kelompok yang sangat kecil sehingga tidak berperan banyak dalam terjadinya trauma lahir kecuali disertai faktor risiko lain.

Penelitian kami, menunjukkan bahwa vakum ekstraksi terbukti berhubungan dengan kejadian trauma lahir. Sesuai dengan hasil penelitian SauberSchatz $\mathrm{dkk}^{15}$ yang melaporkan bahwa persalinan dengan bantuan alat (forseps dan vakum) berperan dalam terjadinya trauma lahir pada $27,2 \%$ dari bayi baru lahir dengan trauma lahir. Suntiwitchaya ${ }^{16}$ melaporkan durasi vakum ekstraksi terbukti sebagai faktor risiko trauma lahir. Sedangkan versi ekstraksi tidak terbukti berhubungan dengan trauma lahir. Hasil tersebut tidak sesuai dengan Garcia $\mathrm{dkk}^{6}$ yang melaporkan bahwa persalinan dengan manuver eksternal merupakan faktor risiko trauma lahir.

Malpresentasi merupakan salah satu faktor risiko yang diduga berkaitan dengan kejadian trauma lahir. Meskipun malpresentasi secara umum tidak terbukti sebagai faktor risiko trauma lahir, tetapi presentasi bokong menjadi faktor risiko trauma lahir. Hasil tersebut sesuai dengan penelitian lain yg mendapatkan bahwa presentasi bokong merupakan faktor risiko trauma lahir dan presentasi bokong juga akan meningkatkan risiko trauma syaraf perifer. ${ }^{6}$ Hoeksma $\mathrm{dkk}^{14}$ mendapatkan hasil bahwa trauma pleksus brakhialis paling sering dijumpai pada persalinan presentasi bokong. Fraktur dijumpai pada semua bayi dengan presentasi bokong yang dilahirkan dengan manuver bracht. ${ }^{15}$ Presentasi muka dan letak lintang tidak menunjukkan sebagai faktor risiko trauma lahir dalam penelitian kami, kemungkinan karena sistem pencatatan dan pelaporan rekam medis yang kurang lengkap dan jumlah subjek yang kurang optimal sehingga akan memengaruhi validitas hasil penelitian.
Seksio Kaisar menunjukkan sebagai faktor protektif terhadap trauma lahir. Angka kejadian trauma lahir menurun drastis pada persalinan dengan seksio kaisaria dibanding dengan cara persalinan normal dan dengan manuver. Hal tersebut mendukung hasil penelitian. Dengan demikian, penggantian tindakan ekstraksi forsep dan vakum dalam persalinan dengan tindakan bedah kaisar dinilai lebih aman untuk bayi. ${ }^{1,2}$ Shreeprasad dan Shilpa ${ }^{3}$ juga mendukung bahwa dengan tindakan seksio kaisar akan mengurangi terjadinya tekanan dan tarikan selama proses persalinan sehingga menurunkan insiden trauma lahir. Penelitian Mosavat dan Zamani ${ }^{5}$ menunjukkan hasil yang sesuai ketika kejadian trauma lahir lebih sering terjadi persalinan pervaginam dibandingkan seksio kaisaria. Penelitian ini juga didukung oleh Puza $\mathrm{dkk}^{17} \mathrm{dan}$ penelitian lain yang menunjukkan bahwa perubahan cara persalinan dengan seksio Kaisar akan menurunkan risiko terjadinya trauma lahir. ${ }^{6}$

Penyulit persalinan merupakan salah satu faktor yang diduga berhubungan dengan trauma lahir, dalam penelitian kami terbukti bahwa penyulit persalinan berhubungan dengan kejadian trauma lahir. Hal tersebut sesuai dengan penelitian Hoeksma ${ }^{14}$ yang menunjukkan bahwa distokia bahu sebagai salah satu penyulit persalinan terbukti berperan terhadap kejadian trauma lahir. Insiden trauma peksus brakhialis (0,5-2 per 1000 kelahiran hidup), 10\% di antaranya berupa Erb palsy dan trauma pleksus brakhialis lainnya terjadi pada persalinan dengan distokia bahu.

Kelemahan penelitian kami adalah data rekam medis yang kurang lengkap sebagai konsekuensi pengambilan data secara retrospektif, serta sistem pencatatan dan pelaporan dalam rekam medis yang kurang terinci berkaitan dengan trauma lahir, penyulit persalinan, dan cara persalinan. Faktor lain yaitu tampak interval kepercayaan yang sangat lebar yang menunjukkan bahwa jumlah subjek terlalu sedikit, tidak memenuhi jumlah subjek yang seharusnya. Hal tersebut akan menimbulkan bias dan akan memengaruhi hasil penelitian. Perlu dilakukan penelitian lanjutan secara prospektif, dengan jumlah subjek yang optimal dan didukung sistem pencatatan data yang lebih lengkap dan akurat.

\section{Kesimpulan}

Faktor risiko trauma lahir adalah malpresentasi (presentasi bokong), persalinan dengan bantuan alat 
(tindakan vakum ekstraksi) dan persalinan dengan penyulit. Seksio kaisaria merupakan faktor protektif terhadap trauma lahir.

\section{Daftar pustaka}

1. Handryastuti S. Trauma lahir. Dalam: Hardiono DP, Handryastuti S, Kurniati N, Pendidikan Kesehatan Berkelanjutan Ilmu Kesehatan Anak XLIX: Pediatric Neurology and Neuroemergency in daily Practice, Badan Penerbit Ikatan Dokter Anak Indonesia; 2006.h.2941.

2. Laroia N. Birth trauma. Department of Pediatrics Division of Neonatology, Golisano Children's Hospital at Strong, University of Rochester; Section Chief of Neonatology, Rochester General Hospital, 2008.

3. Zaman SB, Qamar R, Siddique S, Zulqarnain A, Saleem A. Vaginal delivery versus cesarean section; Birth outcome in primi gravdae breech. Professional Med J 2010;17:300-3.

4. Madiyono B, Moeslichan SM, Sastroasmoro S, Budiman I, Harry Purwanto S. Perkiraan besar sampel. Dalam: Sastroasmoro S dan Ismael S. Dasar-dasar metodologi penelitian klinis. Edisi ke-2, Jakarta: Sagung Seto;2002.h.278-9.

5. Mosavat SA, Zamani M. The incidence of birth trauma among live born term neonates at a referral hospital in Rafsanjan, Iran. J Matern Neonatal Med 2008;5;337-9.

6. Garcia H, Rubio-Espiritu J, Islas-Rodriquez MT. Risk factors for birth injury. Rev Invest Clin 2006;58:41623.

7. Tabatabaei STS. Birth trauma among live born term neonates at a referral hospital in Rafsanjan, Iran. Pak Paed J 2008:32:101-4.

8. Bhat V, Ravikumara, Oumachigui A. Nerve injuries due to obstetric trauma. J Bone Joint Surg Am 2003;85:31622.

9. Enyida CE, Nte AR. Mechanical birth injuries in the niger delta: a ten year review (1989-1998). Trop J Obstet Gynaecol 2005;22:50-5.

10. Perlow JH, Wigton T, Hart J, Strassner HT, Nageotte MP, Wolk BM, Birth trauma. A five-year review of incidence and associated perinatal factors. J Reprod Med 1996;41:754-60.

11. Borna H, Rad SM, Borna S, Mohseni SM. Incidence of and risk factors for birth trauma in Iran. Taiwan J Obstet Gynecol 2010;49:170-3.

12. Das D, Irigoyen M, Patterson MB, Salvador A, Schutzman DL. Neonatal outcomes of macrosomic births in diabetic and non-diabetic women. Department of Pediatrics, Division of Neonatology, Albert Einstein Medical Center, Philadelphia Pennsylvania: USA, 2009.

13. Fabamwo, Disu E, Akinola O, Adewale L Birth trauma in a tertiary maternity unit in South Western Nigeria. Internet J Pediatr Neonatol 2007:7(2). (Diakses 9 Oktober 2013). Didapat dari: http://ispub.com/ IJPN/7/2/5257

14. Hoeksma AF, Anne MtS, Piet D, Rob GHH, Nelissen, Anita $\mathrm{B}$, dkk. Shoulder contracture and osseous deformity in obstetrical brachial plexus injuries. Academic Medical Center, Amsterdam: The Netherlands. J Bone Joint Surg Am 2003;85:316-22.

15. Sauber-Schatz EK, Markovic N, Weiss HB, Bodnar LM, Wilson JW, Pearlman MD. Descriptive epidemiology of birth trauma in the United States in 2003. Paediatr Perinatal Epidemiol 2010;24:116-24.

16. Suntiwitchaya W. Risk factors related to severe birth injury in vacuum extraction delivered infant GA $\geq 37$ weeks at Bhumibol Adulyadej Hospital. Vol.54 No.2 May-August 2008. (Diakses 9 Oktober 2013). Didapat dari: http://thailand.digitaljournals.org/index.php/ RTAMG/article/view/2254

17. Puza S, Roth N, Macones GA, Mennuti MT, Morgan MA. Does cesarean section decrease the incidence of major birth trauma?. Department of Obstetrics and Gynecology University of Pennsylvania Medical Center, Philadelphia: USA. J Perinatol 1998;18:9-12. 